\title{
Reduction of pulmonary capillary blood volume in patients with severe unexplained pulmonary hypertension
}

\author{
Colin Borland, Yolande Cox, Tim Higenbottam
}

\begin{abstract}
Background - Unexplained or primary pulmonary hypertension results in an obliteration and obstruction of resistance pulmonary arteries. In these patients gas exchange is impaired and the measurement of gas transfer for carbon monoxide is usually reduced. This has been thought to represent a reduction in pulmonary alveolar capillary blood volume (Vc). A single breath test, measuring simultaneously the uptake of both nitric oxide (NO) and carbon monoxide (CO), provides a simple and practical measurement of membrane diffusion (Dm) and Vc.

Methods - A standard single breath test for the measurement of gas transfer for carbon monoxide (TLCO) was adapted to include NO (40 ppm) in the inhaled gas mixture and a breathhold time at total lung capacity of 7.5 seconds was used. Twelve patients with primary pulmonary hypertension and 10 similar normal volunteers were studied while seated at rest. Results - The patients had reduced values for Tlco and TLNo. The mean (SD) value of $\mathrm{Dm}$ in the patients was $36.7(32.1)$ mmol/min.kPa compared with 52.8 (23.9) $\mathrm{mmol} / \mathrm{min} . \mathrm{kPa}$ in the normal subjects. Vc in the patients was $0.03(0.03) 1$ and 0.06 $(0.01) 1$ in the normal subjects.

Conclusions - The simultaneous measurement of NO and CO uptake is possible in healthy volunteers and patients with primary hypertension. In these patients capillary blood volume is reduced compared with normal subjects. (Thorax 1996;51:855-856)
\end{abstract}

Keywords: pulmonary hypertension, pulmonary capillary blood volume, nitric oxide, carbon monoxide.

Department of

Respiratory

Physiology,

Papworth Hospital,

Cambridge CB3 8RE,

UK

C Borland

Y Cox

$T$ Higenbottam

Correspondence to: Dr T Higenbottam.

Received 15 April 1993 Returned to authors 13 August 1993 Revised version received 6 March 1996 Accepted for publication 12 March 1996
Severe unexplained pulmonary hypertension, where the histological plexiform abnormalities ${ }^{1}$ or peripheral thrombotic lesions ${ }^{2}$ are associated with obstruction and obliteration of the pulmonary arteries, ${ }^{3}$ causes varying degrees of abnormal pulmonary gas exchange. ${ }^{3-5}$ A widened alveolar-arterial oxygen gradient (DA$\mathrm{aO}_{2}$ ) occurs at rest and increases with exercise. This results from a low pulmonary arterial oxygen tension $\left(\mathrm{PaO}_{2}\right) .^{6}$ In addition, ventilation-perfusion imbalance occurs with an increased dead space and a right-to-left intrapulmonary shunt. ${ }^{6-8}$ The measurement of the carbon monoxide transfer factor (TLCO) is also usually reduced in unexplained pulmonary hypertension. ${ }^{9}$ This has been thought to result from a fall in alveolar capillary blood volume $(\mathrm{Vc})$ as measured by the Roughton and Forster method from TLCO at two oxygen tensions. ${ }^{9}$

We have recently described a method of measuring simultaneously the single breath uptake of carbon monoxide (TLCO) and nitric oxide (TLNO) ${ }^{10}$ which allows the membrane diffusion (Dm) for $\mathrm{NO}$ and $\mathrm{CO}$ to be calculated and $\mathrm{Vc}$ to be estimated from one single breath measure at only one oxygen tension. ${ }^{11}$ We have measured Dm and Vc in a group of patients with unexplained pulmonary hypertension since it is a unique example of a disease which affects the blood vessels rather than the air spaces. The age group affected by the disease allows ready comparison with a matched group of healthy volunteers.

\section{Methods}

The measurements were made using an adapted gas transfer apparatus (Transfer Test, PK Morgan, Chatham, UK). Patients and subjects were studied seated at rest. After exhaling to residual volume they inhaled to total lung capacity a gas mixture of $14 \%$ helium, $0.3 \%$ carbon monoxide (CO), nitric oxide (NO) at 40 parts per million (ppm), $25 \%$ oxygen balanced with nitrogen. The breath was held at total lung capacity for 7.5 seconds followed by a full exhalation. After discarding the first litre the remaining exhaled gas was collected for analysis. The inhaled and exhaled gas mixtures were analysed for helium with a katherpharometer, $\mathrm{CO}$ by an infrared analyser, NO with a chemiluminescentanalyser(Model42, Thermoelectron, Warrington, UK), and oxygen with a paramagnetic analyser. Each patient and volunteer completed three measurements. Immediately after the last measurement $6 \mathrm{ml}$ of venous blood was obtained from an antecubital vein. The blood was analysed for concentrations of haemoglobin, methaemoglobin, and carboxyhaemoglobin using an automated spectrophotometer (IL282, Instrument Laboratories, Andover, Massachusetts, USA). The mean values for TLNO, TLCO, Dm, and Vc were calculated as previously described ${ }^{11}$ :

(1) $\mathrm{DmNO}=\left(\Theta_{\mathrm{NO}}-2 \Theta \mathrm{CO}\right) /\left(\Theta_{\mathrm{NO}} / \mathrm{TLNO}_{\mathrm{LNO}}\right.$ ӨCO/TLCO)

$\mathrm{Dm} \Theta=\mathrm{DmNo} / 2$

(2) $\mathrm{Vc}=1 / \mathrm{C}(\Theta \mathrm{CO} / \mathrm{TLCO}-\Theta \mathrm{C} / \mathrm{DmCO})$.

Twelve patients with unexplained pulmonary hypertension diagnosed by right heart 
Table 1 Mean (SD) data of patients and control subjects

\begin{tabular}{|c|c|c|}
\hline & $\begin{array}{l}\text { Patients } \\
(n=12)\end{array}$ & $\begin{array}{l}\text { Controls } \\
(n=10)\end{array}$ \\
\hline Age (years) & $38.6(10.8)$ & $37.2(9.2)$ \\
\hline Height (m) & $1.7(0.06)$ & $1.7(0.10)$ \\
\hline Male/female & $6 / 6$ & $4 / 6$ \\
\hline Haemoglobin concentration $\left(\mathrm{g} / \mathrm{dl}^{2}\right)$ & $15.7(1.6)$ & $14.4(1.5)$ \\
\hline $\mathrm{FEV}_{1}(\%$ predicted $)$ & $71 \quad(25)$ & 110 \\
\hline $\mathrm{TLCO}(\mathrm{mmol} / \mathrm{min} / \mathrm{kPa} / \mathrm{l})$ & $5.8(1.2)$ & $9.3(2.0)^{\star \star \star}$ \\
\hline TLNO $(\mathrm{mmol} / \mathrm{min} / \mathrm{kPa} / \mathrm{l})$ & $29.1 \quad(7.5)$ & $41.9(10.4)^{\star \star}$ \\
\hline $\mathrm{Dm}(\mathrm{mmol} / \mathrm{min} . \mathrm{kPa})$ & $36.7 \quad(32.1)$ & $52.8(23.9)$ \\
\hline Vc (l) & $0.03(0.03)$ & $0.06(0.01)$ \\
\hline Mean Ppa (mm Hg) & $65.9(15.8)$ & - \\
\hline Pulmonary vascular resistance $(\mathrm{mmHg} / \mathrm{l} . \mathrm{min})$ & $19.9(6.7)$ & - \\
\hline
\end{tabular}

$\mathrm{FEV}_{1}=$ forced expiratory volume in one second; $\mathrm{TLCO}_{\mathrm{LCO}} \mathrm{TLNO}=$ carbon monoxide and nitric oxide lung transfer factors; $\mathrm{Dm}=$ membrane diffusion; $\mathrm{Vc}=$ alveolar capillary blood volume; PPA $=$ pulmonary artery pressure.

catheterisation were studied. All the pulmonary hypertensive patients were receiving maximal tolerated vasodilator treatment: six were on long term intravenous infusion of prostacyclin, three were on infusions of iloprost, a prostacyclin analogue, and three were on oral diltiazem, a calcium channel blocker (120 mg three times daily). None had evidence of cardiac or pulmonary disease. Their pulmonary ventilation and perfusion scintograms were normal so excluding pulmonary emboli. Dynamic lung volumes were recorded with dry wedge spirometers (Vitalograph Ltd, Buckingham, UK). Dynamic lung volumes were also measured in 10 healthy volunteers recruited from hospital staff. No patient or volunteer was a current cigarette smoker.

The study was approved by the hospital ethics committee and all participants gave written informed consent.

\section{Results}

The patients and volunteers had similar ages, heights (table 1), sex distribution, and haemoglobin. The patients with pulmonary hypertension had smaller dynamic volumes than the volunteers, indicated by the lower value for forced expiratory volume in one second $\left(\mathrm{FEV}_{1}\right)$ (table 1). Their mean pulmonary pressure and pulmonary vascular resistance were raised compared with the volunteers, and TLCO and TLNO values were significantly reduced to $37.5 \%$ and $30.6 \%$, respectively, below the values of the volunteers. Dm for the patients was not significantly less than for the volunteers but the Vc was lower in the patients (table 1).

\section{Discussion}

We have applied a new measurement of gas transfer factor, which uses simultaneous recording of the uptake of both NO and CO on inhalation, to patients with severe pulmonary hypertension. The patients had lower values for TLCO and TLNO than a group of volunteers with similar anthropometric characteristics.

Significantly lower values of Vc were found in the patients. The value of $\mathrm{Dm}$ was also reduced but this did not reach statistical significance. No statistically significant differences emerged between the treatments but the numbers studied were small.

The lower Vc may reflect the reduction in cardiac output ${ }^{12}$ which is a characteristic finding in severe pulmonary hypertension. ${ }^{13}$ The reduction in cardiac output is a measure of severity of the disease and represents the haemodynamic result of the obstruction and obliteration of the pulmonary arteries. ${ }^{3}$ Over $80 \%$ of the resistance pulmonary arteries of 80-120 $\mu \mathrm{m}$ diameter are "lost" in these patients by the time they are diagnosed. ${ }^{14}$ An adaptation which allows survival is the development of collateral vessels which bypass the obstructed and narrowed resistance vessels. Although this will lower resistance, such vessels may not be accessible to inhaled oxygen, NO, or CO. ${ }^{15}$ However, the adaptation is unlikely to allow full recovery of normal capillary volume leaving Vc reduced in value. Whether this contributes to impaired gas exchange is unclear; TLCO is measured at total lung capacity during apnoea whereas gas exchange occurs during tidal breathing. If $\mathrm{Vc}$ is low in these patients while breathing tidally, it could contribute to hypoxia by shortening capillary transit time or by increasing the capillary resistance to oxygen transfer $\left(1 /\left(\Theta_{2}\right) \mathrm{Vc}\right)$. In patients with unexplained severe pulmonary hypertension impaired gas exchange is not only due to imbalance of ventilation and perfusion but might also result from a reduction of alveolar capillary blood volume.

1 Wagenwoort CA, Wagenwoort N. Primary pulmonary hypertension: a pathologic study of lung vessels in 156 clinically diagnosed cases. Circulation 1970;42:1163-84.

2 Bjornsson I, Edwards ND. Primary pulmonary hypertension. Mayo Clin Proc 1985;560:16-25.

3 Reid LM. Structure and function in pulmonary hypertension. Chest 1986;89:279-88.

4 Gazetopoulas N, Salonikidies N, Davies H. Cardiopulmonary function in patients with primary pulmonary nary function in patients with prim

5 Jones NL, Goodwin JF. Respiratory function in pulmonary thromboembolic disorders. BMf 1965;1:1089-93.

6 Otulana B, Higenbottam TW. The role of physiological deadspace and shunt in the gas exchange of patients with pulmonary hypertension: a study of exercise and prostacyclin infusion. Eur Respir f 1988;1:732-7.

7 Dantzker DR, Bower JS. Mechanisms of gas exchange abnormality in patients with chronic obliterative pulmonary vascular disease. 7 Clin Invest 1979;64:1050-5.

8 Dantzker DR, Bower JS. Pulmonary vascular tone improves VA/O matching in obliterative pulmonary hypertension. $\mathscr{f}$ Appl Physiol 1981;51:607-13.

9 Nadel JA, Gold WM, Burgess JH. Early diagnosis of chronic pulmonary vascular obstruction. Value of pulmonary function tests. $A m \mathcal{F}$ Med 1968;44:16-24.

10 Borland CDR, Higenbottam TW. A simultaneous single breath measurement of pulmonary diffusing capacity with nitric oxide and carbon monoxide. Eur Respir f 1989;2:5663.

11 Borland CDR, Cox Y. Effect of varying alveolar oxygen partial pressure on diffusing capacity for nitric oxide and carbon monoxide, membrane diffusing capacity and lung capillary blood volume. Clin Sci 1991;81:759-65.

12 Davies NJH. Does the lung work? What does the transfer of carbon monoxide mean? Br 7 Dis Chest 1982;76:105-24.

13 D'Alonzo GE. Survival in patients with primary pulmonary hypertension. Ann Intern Med 1991;115:343-9.

14 Reeves JT, Noonan JA. Microarteriographic studies of primary pulmonary hypertension. Arch Pathol 1973; 95:50-5.

15 Smith P, Heath D, Yacoub M, Madden B, Coslin A, Gosney J. The ultrastructure of plexogenic pulmonary arteriopathy. F Pathol 1990;160:111-21. 